\title{
Frege: The Theory of Meaning Concerning Proper Names
}

Sikander Jamil

\section{Preliminary Remarks}

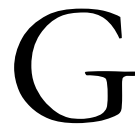

ottlob Frege may be considered as the first intellectual giant in the Philosophy of Language. He was the first to raise the issue of meaning by formulating an organized theory of meaning for a part of natural language as the theory of meaning is at the core of philosophy of language. He emphasizes that the meaning of a sentence directly depends on the meaning of its constituent parts. That is why he has to dissect the internal structure of a sentence or complex expressions provided by a logical syntax, while the truth value of such sentences may be revealed by logical semantics which can be put forward by treating these sentences as a whole.

Hence, in order to move into the Frege's theory of meaning deeply, the treatment of sentences will have to be taken both semantically and syntactically, as he did not propose a sharp distinction between syntactic and semantic treatment of sentences. He is concerned about determining truth value of sentences which in turn is to be decided by the latter. Jefffrey C. King and UC Davis point this issue out:

A primary purpose of semantics for a natural language is to compositionally assign to sentences semantic values that determine whether the sentences are true or false. Since natural language contain contextually sensitive expressions, semantic values must be assigned to sentences relative to contexts. These semantic values are propositions . . .. Propositions are the primary bearer of truth and falsity. ${ }^{1}$

It is in this context that the theory of meaning can be called as organized. For the first time sentences of a considerable part of language may be treated as true or false and hence logic came into existence. The logic could

1 Jeffrey C. King and UC Davis, "Tense, Modality, and Semantic Values," in Philosophical Perspectives, 17, Language and Philosophical Linguistics, ed. by John Hawthorne \& Dean Zimmerman (2003). 
not only provide the rules of inference but could also demonstrate their validity by deriving true conclusions from true premises.

The theory of meaning fundamentally contains two ingredients, i.e., theory of sense and reference, and the other is the theory of force. The latter may be described in Michael Dummett's words:

. . . to the sense of a sentence belongs only that which is relevant to determining its truth or falsity; any feature of meaning which cannot affect its truth or falsity belongs to its tone. Likewise, to the sense of an expression belongs only that which may be relevant to the truth or falsity of a sentence in which it might occur; any element of its meaning not so relevant is part of its tone. ${ }^{2}$

Dummett talks about such feature of meaning that is not going to affect the semantic value of a sentence. For instance, in any sentence of a fragment of natural language, if we substitute a word, say, 'for' in place of 'and', then the meaning of that sentence will distort but this substitution is not going to alter the truth value of that sentence, it was this kind of feature of meaning which Dummett talks about. Wang Lu pointed out that:

It is clear that this framework is based on some of Frege's concepts. Dummett took the theory of reference and sense as the principal of the theory of meaning, which is exactly the primary content of Frege's philosophy of language. That he regarded the theory of reference as the central concept directly coincides with Frege's formulation. Dummett takes Frege's entire formulation of reference to constitute the core of the theory of meaning. Hence, the theory of meaning should inherit Frege's results of reference and take them as the basis of discussion and development. To this extent, the central core of the theory of meaning clearly correlates with reality and truth, because the core of Frege's theory of meaning is the notion of truth. ${ }^{3}$

Wang Lu portrays the picture of the theory of meaning which put fundamental emphasis on the theory of reference and which is conceptually directed towards the concept of truth. The proper name is one of the most striking feature of the theory of meaning which is roughly based on the notion

\footnotetext{
1981), 2.

${ }^{2}$ Michael Dummett, Frege: Philosophy of Language, second edition (London: Duckworth,

${ }^{3}$ Wang Lu, "Theories of Meaning," in Frontiers of Philosophy in China, 3: 1 (2008), 2.
} 


\section{THE THEORY OF MEANING}

of reference ( as we will see later), reference being the meaning of proper name. Mark Platt observed that 'The meaning of a proper name is its bearer."

Hence, our discussion will confined to the theory of sense and reference which also consists of two ingredients inseparably connected to each other, i.e., the theory of sense and the theory of reference. The former is concerned with the issue of meaning while the later is the principle on which former rests (which in turn is cohesively tied to the notion of proper names).

The essence of Frege's philosophy of language lies on the fact that he was actually concerned about formulating a theory of meaning which is inseparably connected to the theories of sense and reference. Dummett possesses a uniform approach regarding Frege's theory of meaning and it seems that, in most of the part of his work, he had been successful in displaying this approach of Frege.

As we will later observe, Dummett contributes much in explaining the theory of meaning of Frege (however, he was not always successful in his attempts to do so) and at the same time reflecting his own ideas on the subject.

Apart from the theory of meaning of Frege, his earlier works Begriffschrift and Grundlagen was dedicated to invent a symbolic language in which any mathematical propositions can be framed to bring about the presentation of proof which such mathematical assertions provide. By describing the structure of sentences his objective was to justify the truth values assigned to them and the ways by which rules of inference used to understand these sentences may also be justified. Dummett claims that:

The analysis of language which Frege undertook involved on analysis of the working of language. Frege didn't content himself with finding a characterization of the totality of sentences of the symbolic language nor with a mere stipulation of the rules of inference he thought it adequate to employ. Rather the description of the structure of sentences of this language was accompanied by an account of the way in which their truth values were determined and the rules of inference laid down were then seen to be justified by the rules governing assignment of truth values. ${ }^{5}$

Frege could recognize the two intimately related semantic properties in the theory of meaning, i.e., Meaning (Bedeutung) and Sense (Sinn). He found that this new discovery didn't contradict to his earlier works rather it made his theory even more plausible and clear. He could visualize what sort of analysis he worked with.

4 See also Mark Platts, Ways of Meaning An introduction to a Philosophy of Language (London: Routledge \& Kegan Paul, 1979), 134.

${ }^{5}$ Dummett, op cit., 81. 
The theory of meaning which Frege proposes, an analysis provided by such theories, which stands for particular atomic sentence such as "Peter is wise." A sort of system had been provided in which the truth value of the atomic sentence may be determined which seems to be the ultimate objective of the theory of meaning suggested by Frege.

The singular expression ${ }^{6}$ 'Peter' serves the functioning of introducing an object, which is in turn, is a matter of function to be augmented. The function is in turn introduced by the concept expression ' $\xi$ is wise', which is formed by omitting a proper name, i.e., 'Peter.' Putting any proper name in place of ' $\xi$ ', satisfying the corresponding object, i.e., wise object, the concept expression will yield an atomic sentence, which is determined with the possession of truth value (in terms of possessing significance of a complete sentence).And this function presents only such object, i.e., wise object on to the truth value as true.

On the one hand a proper name may fail to correspond an object and hence devoid of meaning and also fail to present an atomic sentence in which it lies with an argument to the function stipulated with concept expression. Any such atomic sentence will be devoid of any truth value. Frege authorize it by stating that the sentence is neither true nor false. It simply shows that the sentence falls short of having any truth value at all. Dummett suggested elsewhere that Frege was thinking of a third value which is a member of the undesignated value class.

If Frege would have recognized such third value, then his concepts would have treated objects as per broader category of entities, in this case too a sentence would have devoid of any truth value, as there is no argument displayed to the function that is appropriate. ${ }^{7}$

Secondly, a concept expression may fall short of introducing a function which makes objects truth value. In case, a partiality is found in the function of concept expression, and then is simply devoid of any meaning because such expressions can't be used in general language to make some significant assertions regarding the facts.

And if such expressions are allowed then naturally some atomic sentences would display the absence of truth value, particularly universally quantified sentences. Frege, regarding empty singular terms concerning their meaning, points out in his unpublished work 'Seventeen Key Sentences on Logic':

A sentence can be true or untrue only if it is an expression for a thought. The sentence 'Leo Sachse is a man' is the expression of a thought only if 'Leo Sachse' designates something. And so too the sentence ' this table is round' is the expression of a thought only if the

\footnotetext{
${ }^{6}$ Frege calls all singular expressions generally as proper names. See also Dummett, op cit., 54 .

${ }^{7}$ See also Gareth Evans, The Varieties of References, ed. by John McDowell (New York, Clarendon Press: Oxford University Press, 1982), 11.
} 
words 'this table' are not empty sounds but designate something specific for me. ${ }^{8}$

In Grundlagen, Frege expresses a point of singular terms or proper names) which seems to be closer to the conception of Russell, i.e., the significance of singular terms depend upon its possessing a referent. Any atomic sentence containing empty singular term can't be uttered by someone a sentence would fail to express a thought. Frege maintains that "The sentence "Leo Sachse is a man" is the expression of a thought only if "Leo Sachse" designates something." "

It is plausibly clear that any proper name like "Leo Sachse" has got significance in any sentence of thought expression if and only if, it designates something as a concrete object, in the absence of later, being an empty proper name, the proper name would fail to express a thought. And therefore the sentence in which it occurs would not express any truth value. ${ }^{10}$ While, in 'The thought' Frege further asserts that:

But if my intention is not realized, if I only think I see without really seeing, if on that account the designation 'that lime tree' is empty, then I have gone astray into the sphere of fiction without knowing it or wanting to. ${ }^{11}$

But it seems a matter of great surprise that Frege contradicts his own previous work regarding the stipulation of a proper name with its reference. In above quote, Frege tries to deal with that part of natural language which we may call 'fiction.' Now, his position seems to be quite unjustifiable here as he tries to put emphasis on fiction to ascribe sense to empty proper names.

It is worthwhile to present a separate account for the theory of sense and theory of reference concerning proper names (the theories taken separately, in fact, is an integrated approach of the theory of meaning, as per the views of Dummett) in order to reveal the significance of each theory in isolation from the another and the effect of their synthesis in the theory of meaning.

The main aim of this article is to show the notion of proper names in the theory of meaning of Frege by acquiring the methodology of exploring the theory of sense and the theory of reference. Taken separately and a synthesis of both the theories (in the light of proper names) presents Frege's theory of meaning in a more comprehensive and plausible manner.

8 Frege, Posthumous Writings, 174.

9 Ibid., 175.

${ }^{10} \mathrm{I}$ am not thinking of any third undesignated value as Dummett did. I mean the truth value of that sentence would simply be beyond truth, i.e., it will be neither truth nor false and it would be simply meaningless

11 See "The thought," in P.F. Strawson ed., Philosophical Logic, trans. by A.M. and Marcelle Quinton (Oxford: Oxford University Press, 1967), 28. 
The article briefly argues that the theory of speech acts (including the approach of J.L. Austin and John R. Searle) presents an evolutionary approach (of meaning, in the process of communication) over Frege's theory of meaning.

\section{Theory of Sense Concerning Proper Names}

A preliminary remark to the concept of sense may be traced from the letter written by Frege to Philip Jourdain in 1914:

Let us suppose an explorer traveling in an unexplored country sees a high snow capped mountain on the northern horizon. By making inquiries among the natives he learns that its name is 'Aphla.'By sighting it from different points he determines its position as exactly as possible, enter it in a map, and writes in his diary: 'Aphla' is at least 5000 meters high.' Another explorer sees a snow capped mountain on the southern horizon and learns that it is called 'Ateb.'He enters it in his map under his name. Later comparison shows that both explorers saw the same mountain. Now the content of the proposition 'Ateb' is Aphla' is far from being mere consequences of the principle of identity, but contains a valuable piece of geographical knowledge. What is stated in the proposition 'Ateb is Aphla' is certainly not the same thing as the content of the proposition 'Ateb is Ateb.' Now if what corresponds to the name 'Aphla' as part of the thought was the meaning of the name and hence mountain itself, then this would be the same in both thoughts. The thought expressed in the proposition 'Ateb' is 'Aphla' would have to coincide with the one in 'Ateb' is 'Ateb', which is far from being the case. What corresponds to the name 'Ateb' as part of the thought must therefore be different from what corresponds to the name 'Aphla' as part of the thought. This can not therefore be the meaning which is same for both names, but must be something which is different in the two cases, and I say accordingly that the sense of the name 'Ateb' is different from the sense of the name 'Aphla.' 12

Frege describes sense as a mode of presentation. He seems to focus on stipulating the path from proper name to its referent. In present metaphor used by Frege, 'Aphla' and 'Ateb' are the two ordinary proper names used by the two travelers. Later geographical discovery will demonstrate that it was

${ }^{12}$ Frege, Philosophical and Mathematical Correspondence, 80. 
one and the same mountain encountered from two different sides by the two travelers. Hence, these proper names and thus propositions containing them express different senses but same referent, but before the geographical discovery. After the discovery of the names having same referent, these names will possess same sense also. Now, the names are identity terms, i.e., by substituting one term for another in any proposition, is not going to alter its truth value (Lewis principle of identity).Hence, these names no more display different senses but their senses will also be the same as every competent speaker of language is expected to encounter these names in the same way and thus attaching the same sense to these two names. Gareth Evans holds:

Frege's idea was that it may be a property of a singular term as an element of a public language that in order to understand utterances containing it, one must not only think of a particular object, its meaning but on think of that object in a particular way, i.e., every competent user of the language who understands the utterances will think of the object in the same way. ${ }^{13}$

The theory of sense must provide understanding of the content present in the sentence, i.e., the subject matter of sentence. John McDowell holds similar view, ". . . a theory of sense must fix the content of the saying which on intentional utterance of the sentence could be understood to be."14

In the metaphor provided by Frege, sentence such as 'Aphla is over 5000 meters high' containing singular expressions/ordinary proper names 'Aphla' has got truth value if and only if the mountain is over 5000 meters high. There must be some justification of the correspondence between singular expressions and description attached to it. In other words, the sense of these two proper names should be same (once the discovery that two proper names are referring the same referent, i.e., same mountains, has been made), if this is not the case, then the meaning of sentences used in expressing a thought about that mountain will be affected and as a result of which truth value of these sentences and hence their semantics will automatically be distorted, which is essentially against the objective of the theory of meaning.

But it is not plausible to think that everybody has to think over sentence containing any particular expression in some particular way, i.e., particular sense must be attached to a particular proper name.For instance, it is not possible that everyone is able to determine the height of the mountain ('Aphla' or 'Ateb') as over 5000 meters high, by themselves (therefore they are not quite sure about the height of the mountain).They may only believe in the

\footnotetext{
${ }^{13}$ Evans, op cit., 16.

${ }^{14}$ John McDowell, "On the Sense and Reference of a Proper Name," in Reference, truth and reality (essay on the philosophy of language), ed. by Mark Platts (London: Routledge \& Kegan Paul, 1980), 142.
} 
testimony of others regarding the same. That's why; they will ascribe different senses to either of two proper names ${ }^{15}$.

Here, the definite descriptions attached to both proper names, i.e., .' . . is at least 5000 meters high' is subject to empirical investigation and therefore doesn't reflect truth necessarily ${ }^{16}$ (both travelers might have used wrong or not the right method to determine the height of the mountain or earth crust might have been shifted downward because of high gravitational pull or by some other remote cause). 'Aphla' may be differentiated from 'Ateb' in being discovered from northern horizon while later may be differentiated from the former in being discovered by another traveler from southern region. Hence, the physical part (I mean the kind of surface, the steepness involved in slope etc.) of 'Aphla' observed by one traveler from northern region will obviously be different from that of 'Ateb' which had been discovered by another traveler from southern region. Therefore, two proper names, i.e., 'Aphla' and 'Ateb' would consist of different senses in spite of having the same referent. Here, it would be what Frege calls different ways of presentation of the same referent (the mountain) which makes the senses of these two names different.

Let us make this point more comprehensible. In order to understand the sense of an expression determined by the object to which it corresponds; one must not only understand this specific object and its meaning but also its mode of presentation, as just has been discussed.

In case a way is provided to the thinker over the subject actually a sense is provided to him. To Frege, a mode of presentation had been provided to the thinker and he attaches sense to it, i.e., 'Aphla.' But what should be the mode of presentation? How can it be provided to the thinker? Is there any method of providing a mode of presentation to the thinker? Perhaps, Frege is silent on these questions.

Frege utters 'The sense of a proper name is grasped by everybody who is sufficiently familiar with the language or totality of designations to which it belongs' ${ }^{17}$. He, in fact, invents the concept of sense to all those expressions which leads to some meaning. In the metaphor used by the Frege, we may say that if somebody understands utterances of the sentence 'Aphla is over 5000 meters high', he must think of it in some particular way.

Dummett maintains that 'In order to understand the sense ascribed to a proper name, one has to think of an object that immediately corresponds to it in a particular way. ${ }^{18}$ The essence of the notion of sense lies in a certain expression occurring in a sentence. The sense of this expression plays a pivotal role in its meaning which corresponds to the specification of the truth value of the sentence in which such expression lies. Sense is one of the most important ingredients in revealing the meaning of an expression. Dummett says:

15 Whenever I use the word 'proper name,' I mean ordinary proper name (not 'logical proper name' as Bertrand Russell holds).

${ }^{16}$ Here I am not providing model argument as Kripke did in his seminal lectures Naming and Necessity.

${ }^{17}$ Frege, Translations, 57.

${ }^{18}$ Dummett, op cit., 17. 
. . . this characterization of the notion of sense serves, indeed, to distinguish sense from other ingredients in meaning; but, for the rest, it is, in itself, purely programmatic. We can get no grasp on the sort of thing which Frege took the sense of a word or expression to consist in without scrutinizing the distinction which he drew between sense and reference. ${ }^{19}$

We may take another classical example used by Frege- 'Morning Star' and 'Evening Star.' These two proper names, too possess different senses, in spite of the fact that both refer to the same referent, i.e., planet 'Venus.' Viewed in the morning, shining planet 'Venus' is called 'Morning Star' while in the evening the same referent is known as 'Evening Star.' The senses expressed by these two proper names in a sentence used in expressing a thought, is different however both consist of only one referent. The names consist of what Dummett calls different cognitive value ${ }^{20}$ ('informative content') which directly provides linkage to the Frege's notion of sense, hence both displays different senses as per their act of cognition (when observed in the morning- the planet 'Venus' is called 'Morning Star', the same referent when observed in the evening, is known as 'Evening Star'). Now, these two identity terms after discovery of being possessed the same referent, should lead towards having the same sense also because any competent speaker of language is aware of the fact that both terms (proper names) lead towards the same referent, i.e., planet 'Venus.' In this way, two routes ${ }^{21}$ are determined by the two terms which moves towards the same referent. Here Frege seems to be concerned about to provide a way towards stipulation of reference through the notion of sense; this idea is later defended by Saul Kripke in his seminal lectures 'Naming and Necessity.' Mark Platts observes that:

The route to the reference, according Frege and, on occasion, Dummett, will be some descriptive specification of the object: an object satisfying that description will be object named. This descriptive content, the sense of the name, will be at least part of its meaning; will be understood, or known, by any speaker with mastery of the name concerned. ${ }^{22}$

But how can we stipulate a reference indicated by a proper name or how can we propose criteria of identification of reference in all instances in which utterances of competent speaker of language remains the same. In the

\footnotetext{
${ }^{19}$ Ibid., 89.

${ }^{20}$ Dummett, op cit., 104.

${ }^{21}$ The word is used by Dummett to show the Frege's notion of sense in serving to provide a route to reference.

22 Platts, Ways of Meaning An introduction to a Philosophy of Language, 135.
} 
cases such as a well known river 'Ganga', there are several objects presented to us which signifies this name, we may inclined towards determining whether or not the object being presented corresponds exactly to the name used by us or in other words the presented object is the bearer of the name.

Now, there are several ways of determining the same referent from different parts of the country in which it spreads-India. And likewise, several descriptions go with it like 'Is it the river which arises from the one single source known as 'Gangotri'?' or ' . . . . . which contains sacred water used in purifying human soul' or ' . . . . . . one of the greatest river of the country.' Hence, so many senses may be attached to the river 'Ganga' as there are so many ways of determining the referent.

Frege guessed that the way in which we talk regarding objects is through description (Russell holds similar view). But we may find it clear that nothing had been observed in Frege's theory of description, to support the claim that the way of thinking regarding any object must affect the understanding of subject regarding any description particularly meant for it. Frege uttered very little regarding ways of presentation of an object generally. However, Frege tried to attach then to the concept of propositional attitude psychology as Gareth Evans holds. The links between these concepts are immediate.

The sense of a sentence depends upon the sense of its constituent parts as Frege held that the only constraint which Frege tries to stipulate what Gareth Evans call 'the intuitive criteria of difference' which indicates that the sense of a sentence, say A, has to be different from the sense of sentence, say, B.

In these two sentences, one can understand both simultaneously considering different attitudes towards them. Taking one as true, while other as false. Frege's conception of sense need to have its linkage with the propositional attitude that may provide solution to the problem-how two sentences consisting of same meaning possess different ways of presentation or different values of cognition (as in case of Frege's classical example-'Morning Star' and 'Evening Star').

Two sentences A\& B have got different cognitive values, in case it is possible to have understanding of these sentences keeping attitudes differently regarding them. From this, it leads to the point that the conception of a way of thinking which is an integrated, inseparable notion of sense has to behave somewhat differently from Evans conception of Intuitive criteria of difference as in former case the same thought is being dealt at different time while in later case we have to deal with the same thought by the same subject in the same time.

From the present discussion, we may conclude that Frege tried to present a system of communication through a sentence which consists of a proper name. The competent speaker of language expresses a particular sentence ' $\mathrm{p}$ is $\mathrm{A}$ ' bearing the thought in his mind, the content of which depends on the sense he ascribe to the singular expression (or proper name) ' $p$ ' and ' $\xi$ is A.' The expression of thought has to be concerned with the 
expression 'A' referent which has to be thought in particular way, which in turn determines its sense.

And the hearer of this sentence understands it and the thought associated with it, in the same way, i.e., having similar truth value as the utterances of the speaker. In this case, the content of thought of the hearer will also have to be determined by the sense he stipulates to the same expression.

On assuming that both speaker and hearer, which are competent speakers of the language, are using objective property of expression of language and both possess a definite sense to it, we may claim that the hearer will receive the same thought as expressed by the speaker.

Frege seems to agree on the point that there may be same instances in which sentences of a natural language consisting of meaning are successful in expressing a thought but still the theory of meaning does not fit here. Empty proper name may contribute in the expression of thought through these sentences without consisting of any semantic value from them as per the conviction of the theory of meaning.

Sense seems to be falling short of being a criterion in the determination of reference for each person is not going to use the same definite description regarding the reference. ${ }^{23}$ But if all competent speakers of language are able to understand that the river 'Ganga' as an object being presented to us, is actually the bearer of the proper name used by them, the conception of determination of reference seems to be quite justified. The main problem arises when a speaker is unaware of the fact that the river is located in India and think of its incorrect location, say, USA. This person may still use the name 'Ganga' but incorrectly (he will use the name with incorrect sense; however he is equipped with a definite criteria in his individual mind). While, if he is said to have understood the word 'Ganga' in its correct sense (i.e. the sense ascribed by the competent users of language, generally), he must be in good command of using correct method of identifying the referent-river named 'Ganga.' Dummett was also aware of this difficulty, he holds, “. . . . that there is no one condition sufficient for identification ...."24

In this way, we may infer that the notion of sense used by Frege, as a part of meaning of a sentence, seems to be subjective and therefore seems to be less significant in the theory of meaning which, in principle, should be equipped with objectivity in linguistic expressions. From the present discussion we may conclude that the criteria of identification of reference are going to vary from person to person in any community of speakers because of the inclusion of subjectivity in the notion of sense. What remain the same uniformly in all instances of identification of reference is the reference as an objective entity which is the meaning of proper name which names the referent. Dummett asserts that, “. . . the only permanent, objective feature of

${ }^{23}$ This is the main point on which Kripke refutes the doctrine of definite descriptions used by Frege and Russell too, in his work entitled Naming and Necessity.

${ }^{24}$ Dummett, op cit., 99. 
the use of a proper name would be its reference, so the only permanent, objective feature of the use of a general term would be its application" 25

But it could be argued that meaning is not something subjective, otherwise it will go on changing from one speaker to another and so on. Meaning must be an objective entity, i.e., subject to empirical investigation. Dummett asserts:

Meaning under any theory of whatsoever, cannot be in principle subjective, because meaning is a matter of what is conveyed by language. Someone may by mistake or design, attach a meaning to some word different from that which anyone else attaches to that word: but the meaning must be something that could be conveyed to another that the person in question was attaching that meaning to the word; if not, it would simply not be a meaning at all. ${ }^{26}$

Frege holds that sense is an ingredient in the intuitive conception of meaning, now it seems to have got no truth value in all situations and in all available contexts in which a sentence(s) is/are being said and heard in any community of speakers, in any fragment of natural language.

Then what significance sense has got in the theory of meaning? In the metaphor used above ('Aphla' and 'Ateb') different senses are reflected by two proper names ${ }^{27}$.The resulting propositions (by using 'Aphla' and 'Ateb' in two propositions) will obviously reveal different meaning for the same referent, i.e., mountain. While, in actual this is not the case. It is in this context that the theory of meaning used by the Frege has got significance.

Now, the scene Frege creates in formulating the theory of meaning seems to be far from the application in natural language. His theory of meaning presents highly ideal quality in the use of language which we can't afford or only apply partially in the language we speak. But the language will have to be always directed towards the ideality in language as per the conviction of Frege because we encounter several problems in our language which can be resolved by applying the theory of meaning, i.e., the theory of reference and sense.

\section{Sense Devoid of Meaning: Void Proper Names ${ }^{28}$}

Gareth Evans already raised objections to the notion of sense devoid of meaning in holding the following:

${ }^{25}$ Ibid., 102.

${ }^{26}$ Ibid., 85.

${ }^{27}$ Whenever I use word-proper name, I mean it in the same sense as Frege, singular expressions generally.

${ }^{28}$ I will prefer to use the word 'void proper names' in place of empty proper names (used by Gareth Evans). 
I have been objecting to Frege's attempt to discern sense where there is no semantic value, essentially on the ground that it deprives a theory of semantic value of any obvious place in the general theory of language. It might be said that Frege thought of the theory of semantic value as needed for the purpose of investigating logical inference. But the theory which Frege offered is adequate for this role only if we assume that the language under study contains no empty singular terms. This is a restriction for which we could find no justification. ${ }^{29}$

Frege's notion of empty proper names reveals that the proper names without any semantic value may still have a sense; this point has got extremely weak foundation as embracing it would only leads to confusion in understanding both sense and semantics of proper names. Evans further asserts:

\begin{abstract}
Names that fail to fulfill the usual role of proper name, which is to name something, may be called mock proper names. Although the tale of William Tell is a legend and not history, and the name 'William Tell' is a mock proper name, we cannot deny it a sense. But the sense of the sentence 'William Tell shot an apple off his son's head.' I do not say that this sense is false either, but I characterize it as fictitious . ... Instead of speaking about fiction we could speak of 'mock thoughts . . ..'30
\end{abstract}

In the above quote it seems plausibly clear that Frege dared to think of sentences which contains what he calls- mock proper names, i.e., proper names used in fiction and in this way these sentences have been able to express mock thoughts which have nothing to do with reality.

In such cases, it is mere assumption that we are engaged in expressing thoughts by means of sentences containing empty proper names, in fact we are deceiving ourselves in doing so for it only lead us to depart from reality and the gap between reality and fiction will become much bigger. And Frege is not to be expected to present such doctrine, being a logician. He said that, "... The logician does not have to bother with mock thoughts ..." "31. Then, why he bothers at the first place to deal with such "mock" assertions. Gareth Evans raises another objection in holding that:

However, given that Frege was content to deal with the intuitive category of singular terms or referring

\footnotetext{
${ }^{29}$ Evans, op cit., 25.

30 Frege, Posthumous Writings, 130.

${ }^{31}$ Ibid., 130.
} 
expressions, this general model of the functioning of singular sentences can not be accepted. For, although I should (and shall) defend the idea that there are many kinds of singular term (paradigmatically, genuine demonstratives) such that, when they are empty, there can be nothing but the illusion of thought expression and of understanding, it seems to be impossible to maintain this position for all the expressions in the rag bag intuitive category. 32

If we were to preserve the notion of empty proper names with the ascription of sense, then we will have to forget the harmony between semantic value and referent of empty proper names. And the solution to this problem as suggested by Evans ${ }^{33}$ in the form of introduction of an empty set to the semantic value of singular term, depending upon its possessing a referent or not, is also seems to be misleading as we will find ourselves soon in the mesh of confusions as in case of "mock" assertions. This solution seems to be just another side of the same coin, i.e., fiction. But in some cases like:

(1) Pluto is the planet of our solar system.

There is nothing like 'Pluto' as planet being its referent ${ }^{34}$. Now, 'Pluto' will still possess semantic value viz., empty set but devoid of any referent in terms of being a planet. However, 'Pluto' will still remain to exist as a heavenly body.As per the conviction of Frege, the sense of this empty proper name would be a particular way of presentation of its semantic value, i.e., no object is being presented as its referent. This semantic value is different from the semantic value in which it used to be a planet.

\section{Theory of Reference Concerning Proper Names}

Wang Lu had already pointed out that, ". . . the theory of meaning should inherit Frege's results of reference and take them as the basis of discussion and development" (already quoted above). Hence, the theory of reference is at the core of Frege's theory of meaning. Reference of an expression serves in the determination of truth value of a sentence occurring in a part of natural language, as it seems to be the only criteria of determining truth value of an expression. It is useful to quote Dummett from above that, ". . the only permanent, objective feature of the use of a proper name would be

\footnotetext{
32 Evans, op cit., 31.

33 Ibid., 32.

${ }^{34}$ International Astronomical Union, on its meeting at Prague (Czech Republic) on August 24th 2006, decided that 'Pluto' will no more included in the category of planets. They did so, on the basis of new definition of a planet (decided by them).
} 
its reference, so the only permanent, objective feature of the use of a general term would be its application" 35

As we have already observed that an expression without any reference may still display the sense reflected by an empty proper name, occurring in a sentence which expresses a thought. Dummett uttered that:

But, once the reference of each word in a sentence has been determined, the truth- value of the sentence is thereby determined. It was just because of this that we were able to assign, on-effectively but determinatively, a truth- value to each sentence in the language of predicate logic, relative to some interpretation which fixed the references of the non-logical constants: and in any case Frege himself is explicit, and insistent, that the replacement in any sentence of some word or expression by another having the same reference leaves the truthvalue of the whole unchanged. It thus appears that the sense of an expression must coincide with its reference, or, at least, that there must be a one-one correspondence between senses and references. Yet, notoriously, Frege held that many senses could correspond to the same reference. How, then, could he find room for such a notion of sense at all? 36

Further he proceeds in holding that:

The solution to the dilemma has already been stated: reference is not an ingredient in meaning. If reference were an ingredient in meaning, then indeed the reference of a word would exhaust-or determine-its sense, since nothing more would need to be known about its meaning in order to fix the truth-value of any sentence in which it occurred. ' ... . . . . But I think that if we seek to understand the claim that reference is not an ingredient in meaning, it will be seen to accord well with Frege's way of looking at the matter, although not with his way of expressing it. ${ }^{37}$

Reference may be known only when one fully understands the meaning provided by it, which is reflected by others ingredients of meaning like sense, tone. Mere presence of reference of any proper name which is obviously its meaning is neither necessary nor sufficient condition of

\footnotetext{
35 Ibid, 102.

${ }^{36}$ Dummett, op cit., 91.

${ }^{37}$ Ibid., 91-92.
} 
understanding a particular reference. There are others factors such as sense, which helps in the determination of reference of a singular expression.

Hence, it has not to be misunderstood that reference is not an ingredient in meaning, as without reference there would be no such thing as meaning. Reference is essentially provides the substratum on which the theory of meaning rests. But to understand the reference, there must be, as Dummett claims, some way of determining it. As per the conviction of Frege, the way is known as 'sense.' Dummett described the idea in asserting that:

'The sense of a word thus consists in some means by which a reference of an appropriate kind is determined for that word. To say that reference is not an ingredient in meaning is not to deny that reference is a consequence of meaning, or that the notion of reference has a vital role to play in the general theory of meaning: it is only to say that the understanding which a speaker of a language has a word in that language . . can never consist merely in his associating a certain thing with it as its referent; there must be some particular means by which this association is affected, the knowledge of which constitutes his grasp of its sense. ${ }^{38}$

Frege thinks that a speaker of any natural language who knows the referent of certain expression expects the hearer to understand the sense of that expression. But the hearer doesn't necessarily possess understanding about the referent, for there may be several singular expressions which are devoid of any reference.

The sense of an expression present in sentence of any part of natural language should correspond to some referent which essentially deals with providing some meaning to that expression. It is not plausible to think that how can there be any sense without having any object, i.e., referent to be sensed about?

Frege asserts that in case of such singular terms it is necessary to understand its sense but to understand its referent is not necessary. Elsewhere he took example of expressions possessing sense but devoid of any reference e.g. 'the celestial body most distant from the earth.' Now, it has a sense, but its existence is doubtful, i.e., it may not have any referent.

Likewise, can the expression 'a round square' have any sense, which is mathematically impossible? In one place Dummett says: "An expression can have sense but lack any reference. This is one of Frege's best known doctrines, and it is one of the hardest to hold in position in his philosophical system taken as a whole." 39

\footnotetext{
38 Ibid., 84.

${ }^{39}$ Ibid., 160.
} 


\section{6}

\section{THE THEORY OF MEANING}

Here, Frege's philosophy of language seems to be shattered, considering the lacunae in his theory of meaning, i.e., sense without reference. $\mathrm{He}$ also considers the case of singular expressions, i.e., proper names without reference-empty proper names (as discussed above). In such cases he says that sentences containing them are devoid of any truth values.

To Frege, if someone accepts a sentence containing empty proper names, then he is forming a belief about the world and not about the language itself. Gareth Evans says that, ". . . But what sense can be made of a belief which literally has no truth value- which is neither correct nor incorrect? It is precisely this incomprehension, so effectively voiced by Dummett that makes Frege's choice of truth values as the semantic values of sentences so opposite" 40 .

Now, it is worthwhile to raise one more significant question- is there any possibility of reference without sense? Let us consider the example of 'Pluto.' Recently, it had been discovered that planet 'Pluto' will be no more in the category of planet in our solar system, being devoid of characteristic of planet. It used to be a planet in our solar system. What sense these singular expressions possess? What will be its mode of presentation as Frege held? The speaker of the language, who is not aware of this fact, will continue to add sense to it. But there seems to be no meaning being revealed by the term 'Pluto' in terms of being a planet. However, reference is there as just a heavenly body present in the outskirts of the orbit of our solar system.

Donald Davidson prescribes that the theory of meaning, as a whole may be comprehended by two methods, i.e., the building-block method (building complex sentences from simpler ones) and the holistic method (starts with complex sentences and then deal with its fragment parts). The first method seems to be fall short of being applied, practically. Second one may be dealt with the application of behavioral aspects of speakers with the sentences occurring in language. In doing so, fragments of sentences may be encountered with, but semantic value of sentences may not be preserved. ${ }^{41}$ Davidson depicts that, ". . . With the building block approach goes the causal theory of proper names, which Saul Kripke, Hilary Putnam and David Kaplan, among others, have done so much to make plausible" 42 .

The causal theory of proper names is basically the causal theory of reference according to which a proper name is introduced by some introducer(s) in some using application of proper name of a certain speech community (baptism). Then the baptized name is stipulated of its reference and this is how a name acquires its referent and stipulated. Davidson interpretation of this theory runs in holding that a name is baptized with a reference subject to its empirical investigation ${ }^{43}$. The other method follows that interpretation of sentences depends on the various using application of proper names applied by various

\footnotetext{
${ }^{40}$ Evans, op cit., 24.

${ }^{41}$ John McDowell, "On the Sense and Reference of a Proper Name," 136.

42 Ibid., 136.

${ }^{43}$ Davidson uses this word.
} 
users on our natural language. Davidson refutes this approach by suggesting that the concept of reference may be dropped as the holistic approach demands empirical investigation, according to him reference falls short of accessing content of the relation between a proper name and its corresponding object. Davidson provides another reason in eradicating the need of reference form the theory of meaning in holding that the problem of reference may be resolved by encountering the distinction between explanation within the theory and explanation of the theory ${ }^{44}$. By using the word within the theory, he means that the concepts contributing in syntactic and semantic values while by using of the theory he is concerned about dealing with truth as a whole or dealing with the truth conditions of the sentences.

But reference dropping from the theory of meaning seems to be quite unjustified as in fact there are not two methods of dealing with the theory of meaning but there is only one, i.e., simultaneous approach of syntactic and semantic treatment of the sentences occurring in a part of language as did by Frege and the output of the theory of meaning is obviously directed towards truth conditions of the sentences. Davidson asserts that "The theory gives up reference, then, as part of the cost of going empirical" 45 .Now, empirical investigation is itself based on the reference. Davidson thinks that the dropping reference does not mean that the semantics had also been dropped. But practically dropping reference would also drop the semantics of the sentences. If he would insist that, in doing so, semantics of the sentences would be preserved, then reference would include itself, however it's name may be changed in the form of description like 'empirical investigation of the theory of meaning which reveals the truth conditions of the sentences.' Hence, Davidson claim of dropping reference is not well directed, it is only reference which determines the semantic value of the sentences.

Conclusively, it may be said that the theory of reference is also one of the most striking and fundamental feature of the theory of meaning which can't be dropped from it and which rests on the notion of proper names and provides semantic value to the sentences. The notion of sense serves the function of providing a way to determine the reference.

\section{The Theory of Speech Acts: An Evolutionary Approach over Frege's Theory of Meaning}

\section{The Approach of Austin}

After going through Frege's theory of meaning, it seems extremely useful to consider the theory of speech acts, as put forward by J.L Austin and John Searle because the theory presents a better picture on the issue of meaning. The theory also tries to demonstrate language as social conventional practice. First, I would like to consider the approach of J.L. Austin.

\footnotetext{
${ }^{44}$ McDowell, "On the Sense and Reference of a Proper Name," 137.

${ }^{45}$ Ibid., 138.
} 


\section{8}

\section{THE THEORY OF MEANING}

Austin claims that there are some utterances which promote actual actions or performances. These utterances may be called as performative utterances. Speech acts are basically those conventional acts which are determined by customs, traditions and belief system of human society. The acts include "I study", "I appreciate", "I marry" etc.

These performative utterances have something to do with actually doing something and are contrary to making statements. According to Austin, statements are being made primarily to pass performative acts like making a request, giving orders, asking for apology etc. These speech acts are determined by a unique feature of utterances which he calls as illocutionary force. The type of speech acts is determined by virtue of these illocutionary forces.

However, if any act has not been performed in actual (due to lack of intentions on the part of doer) then the performative utterance may turn out to be what Austin calls hollow or void ${ }^{46}$. For example, if I promise to perform a certain act without involving any intention to do so then the utterance "I promise" becomes void. The speech act in this case becomes what Austin calls infelicitous. Frege's notion of mock assertions may also promote void performative utterances. These may be the cases of fiction (Frege), acting in a movie (Austin) etc. Austin holds that such uses of language are not serious and are parasitic on general use of language ${ }^{47}$

Contrary to philosophers of language like Frege, Davidson; he looks on hearer's side (i.e. his psychological state) in the process of communication. Austin calls such feature of utterances as perlocution. Frege and Davidson stress too much on truth conditions of sentences but there are other dimensions of utterances that make them infect (without making them false) or infelicitous.

Frege's theory of meaning puts emphasis on the meaning of sentences in terms of its propositional content. Austin's approach preserves this propositional content of the theory along with suggesting some unique features of utterances like illocutionary force, perlocution. By inventing the notion of speech acts, he dared to go beyond truth conditional approach so that the process of communication may be better explained.

\section{The Approach of Searle}

Frege tries to maintain objective aspect in communication. John Searle holds that there are several other dimensions (beyond objective one) which must be taken in to account. The process of communication is not as simple as it seems to be. There lies huge difference between what a speaker mean and what the hearer understands. This is what Paul Grice describes as speaker's meaning and sentence meaning.

46 Austin uses this word in the context of speech acts. I have used the word in the context of proper names which refer nothing in actual (1.2.1).

${ }^{47}$ See also J.L. Austin, How to do things with words (Oxford: Clarendon Press, 1962), 22.

48 See also John Searle, Expression and Meaning (Studies in the theory of Speech acts) (Cambridge: Cambridge University Press, 1979), 30-32. 
Searle claims that sometimes speaker wishes to express more than his utterance. These are the cases of, what he calls, indirect speech acts. Such acts are performed on the basis of speaker's and hearer's common theoretical background including linguistic and non-linguistic expressions, contexts (in which utterances are being made), inferential aspects on hearer's side etc. For example, a speaker may express the sentence "May I ask your name?" .Now he is not getting permission to know the name of the person but wishes to actually know the name. ${ }^{48}$ The speaker intends to produce information to the hearer that a request has been made to know his name. Sometimes a speaker utters a sentence and means something else as in using metaphors.

Searle makes distinction between primary illocutionary act (which is the main intention of the speaker and not spoken literally) and secondary illocutionary act (which is literally uttered). According to Searle, primary illocutionary act is performed indirectly by mean of secondary illocutionary act ${ }^{49}$. For example, a man utters to his servant "Will you keep quiet?" .He actually orders to his servant to be quiet (primary illocutionary act) by putting the question (secondary illocutionary act). Hence, speaker's intention is going beyond his utterance.

But in virtue of what a speaker intends to perform one speech act by mean of another speech act? Searle did not bother to provide a detailed account of this problem. It seems merely a commonsense social conventional practice of language.

In Frege's theory of meaning, the theory of sense and the theory of reference may be explained in terms of the theory of speech acts. Frege describes sense as a mode of presentation. Proper names 'Aphla' and 'Ateb' display different senses (1.2).

Talking in terms of Searle's speech act theory, 'Aphla' and 'Ateb' consist of same primary aspect (obviously when the speaker is aware that both names refer to the same mountain) but secondary aspect is different. Two propositions (in which 'Aphla' and 'Ateb' occurs) refer to secondary illocutionary act. The speaker, who utters these propositions, is actually intends to produce information that both propositions are meant for same mountain, i.e., consist of similar truth value. This is the primary illocutionary act which the speaker wishes to express.

I think that Searle offers better solution to the problem of identity terms. In case of using 'Aphla', the speaker is simply picking out one aspect under which the object is referred, i.e., mountain. The speaker actually wishes to refer (under primary aspect) "the mountain over there which is over 5000 meters high." He intends to pass this information to the hearer so that he may identify his prime intention to generate this utterance. The same may be true of using 'Ateb.' Usage of both proper names ('Aphla' and 'Ateb') suggests that two different aspects have been pick out so that the right object may be

\footnotetext{
48 See also John Searle, Expression and Meaning (Studies in the theory of Speech acts) (Cambridge: Cambridge University Press, 1979), 30-32.

${ }^{49}$ Ibid., 143.
} 
referred, but the primary aspect lies (on the part of speaker and the hearer) in the utterance "the mountain over there which is over 5000 meters high."

There may be still another aspect (which may be called as tertiary) which suggests that both the names 'Aphla' and 'Ateb' refer to the same referent, i.e., mountain.

Reference stipulation and determination is at the core of Frege's theory of meaning. According to Searle's speech act theory, the reference may be determined by the specification of that aspect under which reference is being made. This is what Searle calls primary aspect.

\section{Conclusion}

Frege's treatment of the notion of sense and reference had been fundamentally applied to proper name which suggests the following:

1) Frege tries to present before us, a model in which referring expression may be fitted for direct application to a formalized language like arithmetic. Naturally the same we can't do with the natural language, as the latter possess the characteristic of equipped with context dependence, which is why it seems impossible, the application of the model presented by Frege to natural language. ${ }^{50}$

2) It seems a matter of great surprise that out of the theory of sense and the theory of reference we have arrived to a conclusion that we have discovered a definite way which may be applied for every proper name and its bearer present in our natural language. John McDowell already observes the point "There is, however, not the slightest reason to expect that one could construct, out of such material, a general relational formula true of every name and its bearer." 51 Saul Kripke made a careful treatment of such theory of sense by defending it in the light of propounding a causal theory of reference. 52

3) If we are to embrace the causal theory of reference, then we will have to refute the descriptivist's approach (of Frege and Russell) regarding the behavior of proper names. ${ }^{53}$

4) As far as dealing with the atomic sentences is concerned, i.e., in that the object of our perception is followed by some proper name earlier being its meaning, ${ }^{54}$ Frege's model seems to be quite safe and justified. But dealing with mock thoughts being expressed by some mock assertions contain

50 David Kaplan, Demonstratives (Unpublished work).

51 John McDowell, "On the sense and reference of a proper name," 162.

52 See also 'Naming and Necessity.' I have provided a detailed account of Kripke's conception of causal theory of reference in the next chapter in which Kripke's refutation against Frege and Russell seems to be well directed, but the theory in itself leaves some lacuna which I described in the same chapter.

53 This point may be described as the central theme of present dissertation. Proceeding chapters are devoted to critically analyze the Kripke's refutation of descriptivist's approach (of Frege and Russell).

54 Platts, op cit., 133-138. 
mock proper name. Frege is quite justifiable and this conception seems to be quite illogical, for we possess very tiny knowledge of the extremely complex psyche of human minds, i.e., how human thought run with particular object. And a particular subject about a particular object in such a strange way that it reflects the non existence of that object, then even a thought wouldn't have been expressed. Hence, Frege's model of referring expressions falls short to be applied in natural language.

5) According to Evan's intuitive criteria of difference, when one ascribe a name to a particular object, he attaches competency to the object so named and thoughts thus expressed is qualified by the intuitive criteria while at the same time different subjects thinking of same object but different thoughts have been expressed by the same sentences containing that name.

6) The theory of reference has got its foundation on the notion of proper names which in turn directly affects the theory of sense.

7) The theory of reference is inseparably connected with the theory of meaning which leads to determiner the truth value of sentences by reflecting their semantics which in turn linguistically preserved by the notion of reference. And as a result, ontologically there is an immediate display of an object corresponding to the utterance of a proper name by some speaker of language. Hence, Davidson suggestions to drop the reference from the theory of meaning may not be accepted.

8) Both the theories, i.e., the theory of sense and the theory of reference concerning proper names are nothing but an ingredient in the theory of meaning prescribed by Frege.

9) Both Dummett and Evans agree that the Frege's model of communication is the Ideal one ${ }^{55}$ (for it refers to the claim that we hardly understand one another perfectly). But still, the conception of Proper names serve some purpose of effective communication as linking with the object under consideration. And Frege's model of communication of reference still possesses weight age in its application.

10) To conclude the matter it is worth while to quote Dummett:

... the practice of speaking a language and the theory of meaning which gives an account of that practice can thus not be separated, except in thought: they constantly interact with one other. The notion of sense, therefore, not a mere theoretical tool to be used in giving an account of a language; it is one which, in an inchoate fashion, we constantly appeal to or make use of in our actual practice(as, for instance, when we challenge some one to make precise the sense in which he is using some expression). ${ }^{56}$

\footnotetext{
${ }^{55}$ Dummett , op cit., 105-06.

${ }^{56}$ Ibid., 107.
} 


\section{THE THEORY OF MEANING}

Hence, we can not draw a sharp distinction between the use of natural language and the construction of theories regarding its working. Dummett calls natural language as 'meta-language' (in which there is an expression of the theories regarding its working) and object language (a formalized language for which the theories of meaning/semantics are being constructed).

11) We, as a speaker of some natural language may apply the prescription of these theories to a part our language but not according a formalized pattern but a pattern of our own which leads to the understanding of meaning of sentences we speak. For example, when emphasis is being made to express the sense in which a competent speaker is expressing a thought so that we may understand, as a listener, the same sense of expressed thought put forward by the sentence(s) used for given purpose.

12) The theory of speech acts presents an evolutionary approach over Frege's theory of meaning. Along with preserving truth conditional approach of Frege (what Austin calls locution), Austin suggests some distinctive features of utterances (involved in the process of communication) like illocutionary force, perlocution. For the first time in the history of philosophy of language, Austin dared to move beyond literal meaning of utterances by inventing the notion of speech acts.

13) Searle's speech act theory presents an improved picture of sense and reference by inventing the concept of primary and secondary aspect of the utterances involved in communication. The approach also presents an evolutionary picture over Frege's theory of meaning in a more comprehensive and plausible manner.

Department of Philosopby, Aligarb Muslim University, India

\section{References}

Austin, J.L., How to do things with words (Oxford:Oxford University, 1962).

King, Jefffrey C. and Davis, UC, "Tense, Modality, and Semantic Values," in Philosophical Perspectives, 17, Language and Philosophical Linguistics, ed. by John Hawthorne \& Dean Zimmerman (2003).

Dummett, Michael, "What is a Theory of Meaning?," (II) in G. Evans and J. McDowell (ed.), Truth and Meaning (Oxford: Oxford University Press, 1976).

Frege: Philosophy of Language (London: Duckworth, 1981).

, The Interpretation of Frege's Pbilosopby (London: Duckworth, 1981).

Evans, Gareth, The Varieties of References, ed. by John McDowell (New York: Oxford University Press, 1982).

Frege, G., Posthumous Writings, ed. by Hans Hermes (Chicago: University of Chicago Press, 1979).

Geach, P.T. and Black, Max, Translations from the philosophical Writings of Gottlob Frege (Oxford :Blackwell, 1952). 
Lu,Wang, Theories of Meaning," in Frontiers of Philosophy in China, 3: 1 (2008).

McDowell, John, "On the Sense and Reference of a Proper Name" in Reference, truth and reality (essays on the philosophy of language),Mark Platts (ed.), (London: Routledge \& Kegan Paul, 1980).

Platts, Mark, Ways of Meaning:An introduction to a Philosophy of Language (London: Routledge \& Kegan Paul, 1979).

Searle, John, Expression and Meaning, Studies in the Theory of Speech Acts, (Cambridge: Cambridge University Press, 1979).

Frege, G., "The thought", trans. by A.M. and Marcelle Quinton, in P.F. Strawson (ed.), Philosophical Logic (Oxford: Oxford University Press, 1967). 